\title{
Combined Jellyfish Collagen Type II, Human Stem Cells and Tgf- $\beta 3$ as a Therapeutic Implant for Cartilage Repair
}

Marion Pugliano ${ }^{1,2 \#}$, Xavier Vanbellinghen ${ }^{1,2 \#}$, Pascale Schwinté ${ }^{1,2}$, Nadia Benkirane-Jessel ${ }^{1,2^{\star}}$ and Laetitia Keller $^{1,2^{\star}}$

${ }^{1}$ INSERM (French National Institute of Health and Medical Research), "Osteoarticular and Dental Regenerative Nanomedicine Laboratory", UMR 1109, Faculté de Médecine, FMTS, Strasbourg, France.

${ }^{2}$ Université de Strasbourg, Faculté de Chirurgie Dentaire, Hôpitaux Universitaires de Strasbourg, Strasbourg, France.

\# These authors have equally contributed to this work.

\begin{abstract}
Background: The limitations associated to current therapies for articular cartilage repair led us to develop new strategies of applicable active therapeutic materials. Human mesenchymal stem cells from bone marrow are promising relevant cell sources for cell therapy and regenerative medicine, in particular for cartilage repair. Recently, a new source of non-mammalian collagen type II emerged and represents a promising tool for cartilage tissue engineering.

Methods: To develop a new therapeutic implant for cartilage repair, we combined (i) jellyfish collagen type II as an implant; (ii) active nanoreservoirs of growth factors (TGF- $\beta 3$ ); (iii) adult human mesenchymal stem cells derived from bone marrow.

Results: Our results indicated clearly that (i) the jellyfish collagen type II implant leads to chondrogenic differentiation of mesenchymal stem cells; (ii) the combined implant and active therapeutic TGF- $\beta 3$ as nanoreservoirs lead to chondrogenic gene expression and cartilage differentiation.

Conclusion: We reported here a new stem cell - based therapeutic active implant for cartilage repair. This approach combines jellyfish collagen type II, human stem cells and TGF- $\beta 3$ as a therapeutic implant to improve cartilage differentiation and repair.
\end{abstract}

Keywords: Jellyfish collagen type II; Mesenchymal stem cells; TGF- $\beta 3$ nanoreservoirs; Cartilage repair; Combined therapeutic implant

\section{Background}

Articular cartilage has very limited capacity of regeneration due to a lack of cells and vascularization. Current therapies treating focal cartilage lesions focus on the use of autologous chondrocytes and the use of biomaterials (alginate, collagen I, collagen III) as matrices supporting cell proliferation and differentiation (MACI, matrix-induced autologous chondrocyte implantation) [1,2]. These materials, of natural or synthetic origin, are used as hydrogels or porous sponges. In the clinic, the collagen is used as a membrane shape and is always originating from mammalian such as bovine or porcine: Chondro-Gide ${ }^{\infty}$ AMIC $^{\oplus}$, (Porcine collagen type I and III, Geistlich) [3], Novocart ${ }^{\oplus}$ 3D (Bovine collagen type I and III) [4], CaReS ${ }^{\circledast}$ (Rat collagen I, ArthroKinetics AG) [5], MACI ${ }^{\oplus}$ (Porcine collagen type I and III, Genzyme Biosurgery) [6]. Indeed, collagen is one of the materials most used in the field of cartilage tissue engineering, due to its biodegradability, biocompatibility, low immunogenicity and cell-adhesive properties. Nevertheless, collagen type II is the main represented collagen of the hyaline cartilage tissue, and recently, an unexpected source of non-mammalian collagen emerged (jellyfish marine collagen type II) and leaves open the possibility to overcome the limitations attributed to mammalian collagen use, such as risks of infections (bovine spongiform encephalopathy), initiation of arthritis by inflammation, or rejections due to religious reasons [79]. This new source of marine collagen type II has shown to possess a superior impact on chondrogenesis compared to collagen I scaffold [8]. The Jellagen ${ }^{\star}$ (Cardiff, United Kingdom) is a marine collagen type II extracted from jellyfish, presenting good availability and easy handling. The use of marine sources of collagen type II presents huge advantages for articular cartilage regeneration: high conservation of collagen in the evolution (triple helix conservation) and preservation of the ecosystem (as the ecological environment is at risk with the excessive expansion of jellyfish). This jellyfish-extracted collagen type II material has already shown its capacity for chondrocyte proliferation, biocompatibility and is currently under pre-clinical studies.

Currently applied in the clinic, collagen I and III therapeutic implants are equipped with pre-cultured autologous chondrocyte cells to fill the articular focal lesions [3-6]. Regrettably, this strategy is associated with limitations such as donor site morbidity and dedifferentiation of articular chondrocytes into fibrous cartilage [10-12]. To overcome these limitations, new strategies have been developed to reach the stem cells based therapies. Indeed, Mesenchymal Stem Cells (MSCs) from the bone marrow appear to be the ideal candidates for cartilage repair therapies, due to their capacity of proliferation, immuno-suppressivity, and differentiation into chondrocytes under specific conditions [1316]. Moreover, recent clinical studies concerning cartilage repair, have shown that autologous human MSCs have equivalent or higher potential than chondrocytes after implantation [17].

In the tissue engineering field, with the development of materials of the second generation, active materials were developed to improve the efficiency of tissue regeneration [18]. These materials can be activated by

${ }^{*}$ Corresponding authors: Nadia Jessel, Faculty of Medicine, INSERM, French National Institute of Health and Medical Research and "Osteoarticular and Dental Regenerative Nanomedicine Laboratory”, Strasbourg, France, Tel: +33 368853376; E-mail: nadia.jessel@inserm.fr

Laetitia Keller, Faculty of Medicine, INSERM, French National Institute of Health and Medical Research and "Osteoarticular and Dental Regenerative Nanomedicine Laboratory", Strasbourg, France, E-mail: Ikeller@unistra.fr

Received March 06, 2017; Accepted March 20, 2017; Published March 27, 2017

Citation: Pugliano $M$, Vanbellinghen $X$, Schwinté $P$, Benkirane-Jessel $N$, Kelle L (2017) Combined Jellyfish Collagen Type II, Human Stem Cells and Tgf-B3 as a Therapeutic Implant for Cartilage Repair. J Stem Cell Res Ther 7: 382. doi: 10.4172/2157-7633.1000382

Copyright: (C) 2017 Pugliano M, et al. This is an open-access article distributed under the terms of the Creative Commons Attribution License, which permits unrestricted use, distribution, and reproduction in any medium, provided the original author and source are credited. 
the addition of active molecules and have already shown their efficiency in the osteoarticular repair domain. Specifically for articular cartilage regeneration, the transforming growth factor- $\beta 3$ (TGF- $\beta 3$ ) was tested in association with materials to increase articular tissue repair efficiency [19-23]. TGF- $\beta 3$ is a major driver of chondrogenesis and endochondral development [24] and was already incorporated within collagenic [22] or within polymeric [25] scaffold to increase their chondrogenic potential. However, a lot of these materials were made active by the incorporation of active molecules in the scaffold itself, leading to an uncontrolled release depending on the degradation rate of the scaffold. Yet, the efficiency of active material on tissue engineering depends on the way they are released. To design an active implantable material is a huge challenge, having to meet the expectations of active molecules, material diffusion, and body responses such as host proteolytic activity after implantation. The development of a therapy in which MSCs and active materials are implanted directly into cartilage defect sites necessitates a controlled release system providing sustained local delivery of TGF- $\beta 3$, to ensure therapeutic efficacy of the implanted MSCs constructs.

In our group, we have reported an innovative strategy based on nanoreservoirs technology by entrapping active therapeutic agents, with a cell-contact dependent release [26-29]. This strategy was used not only for bone repair but also for cartilage regeneration, based on the use of active nanofibrous implant equipped with nanoreservoirs of growth factors combined with stem cells [30-32]. The main aim of this work is to develop a new therapeutic implant for cartilage repair by combining jellyfish collagen type II as an implant, to avoid the collagen type I or III of mammalian origin, growth factors TGF- $\beta 3$ and adult mesenchymal stem cells derived from bone marrow.

To functionalize our jellyfish implant with TGF- $\beta 3$, we use our nanoreservoirs technology (cell - contact dependent release). The efficiency of this new active collagen type II implant, equipped with nanoreservoirs of TGF- $\beta 3$ and stem cells, was evaluated for chondrogenic gene expression and cartilage differentiation.

\section{Methods}

\section{Collagen type II implants preparation}

Rhizostoma pulmo jellyfish type II collagen solution (Jellagen'; 3 $\mathrm{mg} . \mathrm{mL}-1$ in $0.1 \mathrm{M}$ acetic acid) was used to prepare implants. Collagenic materials were first obtained by freezing at $-80^{\circ} \mathrm{C}$ and then freezedrying Jellagen ${ }^{\star}$ solution. Afterwards, lyophilisates were chemically cross-linked with the water-soluble chemical cross-linker N-(3Dimethylaminopropyl)-N'-ethylcarbodiimide hydrochloride (EDC, Thermo Fisher Scientific; $1 \%(\mathrm{~m} / \mathrm{v}))$ for 90 minutes, rinsed with water, and incubated in glycine (GE Healthcare; $1 \%(\mathrm{~m} / \mathrm{v})$ ) for $12 \mathrm{~h}$. For further experiments, collagen II implants were then rinsed with PBS, and sterilized by 30 -minutes exposure to UV light.

\section{Formation of therapeutics TGF- $\beta 3$ nanoreservoirs on collagen type II implants}

Nanoreservoirs technology was performed to add nanoreservoirs of TGF- $\beta 3$ on the native collagen type II (Jellagen ${ }^{\circledR}$ ) implant. For that, the native collagen type II implants were dipped consecutively (6 times during 15 minutes) in alternate solutions of (i) an excipient: chitosan (CHI, Protasan UP CL 113, Novamatrix, Sandvika, Norway; $500 \mathrm{mg} \cdot \mathrm{mL}-1$ ) and (ii) a solution of recombinant human TGF- $\beta 3$ (Euromedex, France; 200 ng. $\mathrm{mL}^{-1}$ ) containing heparin (Sigma-Aldrich, France; $\left.500 \mu \mathrm{g} \cdot \mathrm{mL}^{-1}\right)$. These solutions were prepared in a buffer solution of Tris/ $\mathrm{NaCl}(20 \mathrm{mM} / 0.15 \mathrm{M})$ at $\mathrm{pH}$ 7.4. Each bath was followed by a rinsing step in a solution of Tris/ $\mathrm{NaCl}$ buffer. For further cell culture with mesenchymal stem cells, the TGF- $\beta 3$ active implants were then rinsed with culture medium without serum.

\section{Human mesenchymal stem cells culture}

Human Mesenchymal Stem Cells (hMSCs) from the bone marrow (Promocell, Heidelberg, Germany) were cultured in a proliferation medium (Promocell, Heidelberg, Germany) complemented with supplement mix serum (Promocell, Heidelberg, Germany). The cells were incubated at $37^{\circ} \mathrm{C}$ in a humidified atmosphere of $5 \% \mathrm{CO}_{2}$. When cells reached subconfluence, they were harvested with trypsin and cultured at the density of $3.2 .10^{5}$ cells/material on collagen type II jellyfish implants functionalized (F) or not (NF) with TGF- $\beta 3$ nanoreservoirs. Cells were cultured during 21 days in standard chondrogenic medium without addition of TGF- $\beta 3$ (Lonza, France).

\section{Scanning electron microscopy (SEM) observations}

To verify the addition of nanoreservoirs on the jellyfish collagen type II implants, samples were fixed just after performing nanoreservoirs technology with $4 \%(\mathrm{~m} / \mathrm{v})$ paraformaldehyde, during 10 minutes at $4^{\circ} \mathrm{C}$. They were then dehydrated in successive ethanol baths of increasing concentration degree, and carbon-coated for further observations with a Hitachi S800 scanning electron microscope at $15 \mathrm{kV}$ (Hitashi, Tokyo, Japan).

\section{Biocompatibility}

The biocompatibility of MSCs with the TGF- $\beta 3$ active implants was analysed by measuring metabolic activity of cells with an Alamar Blue ${ }^{\circ}$ test (Thermo Fisher Scientific, Waltham, MA, USA) at different times of culture (days D3, D7, D14, D21). For that, the cells were cultured during 4 hours in a solution of Alamar Blue ${ }^{\infty}(10 \%(\mathrm{v} / \mathrm{v})$ in complete medium without phenol red). Duplicates of each culture medium well were then analysed with a spectrometer (FC Multiskan) at the 570 and $595 \mathrm{~nm}$ wavelengths to determine the $\%$ of Alamar Blue ${ }^{\infty}$ reducti on. For each test, $\mathrm{n}=3$. The $\mathrm{p}$ value was determined by a t test.

\section{Indirect immunofluorescence}

To verify the expression of proteins specific of the articular cartilage tissue, we performed indirect immunofluorescence against Sox9, aggrecan, collagen II and Runx2 for MSCs cultured on the jellyfish implants equipped (F) or not (NF) with TGF- $\beta 3$ nanoreservoirs. For that, cultured samples were fixed with $4 \%(\mathrm{~m} / \mathrm{v})$ paraformaldehyde during 10 minutes at $4^{\circ} \mathrm{C}$, rinsed with PBS, embedded in OCT Tissue $\mathrm{Tek}^{\star}$ (Optimum Cuttin g Temperature; Fisher Scientific, France) and frozen before being cut with a cryostat (Leica CM 3000). Then, samples were saturated and permeabilized with a solution of Triton X-100/BSA $(0.1 \% / 1 \%,(\mathrm{~m} / \mathrm{v}) /(\mathrm{m} / \mathrm{v}))$. The primary antibodies $(1 / 200)$ were then added to the samples at room temperature during $2 \mathrm{~h}$. Rabbit antiSox9 (Sigma-Aldrich), rabbit anti-Runx2 (Sigma-Aldrich), rabbit antiaggrecan (Santa Cruz Biotechnology, TX, USA), and rabbit anti-collagen II (Sigma-Aldrich) were used. After 3 rinses with PBS, 488 Alexa Fluor anti-rabbit (Molecular Probes; Life Technologies, Fisher Scientific, France) $(1 / 200)$ was added during $1 \mathrm{~h}$ at room temperature. PBS rinses were made and a DAPI (Sigma-Aldrich) solution (200 nM) was then added to the samples to stain cell nuclei. For further observations with an epifluorescent microscope (Leica DM 4000B), the samples were mounted with Dako ${ }^{\oplus}$ (Dako, Courtaboeuf, France).

\section{Histology}

To evaluate the chondrogenesis of MSCs growing on jellyfish implants functionalized (F) or not (NF) with TGF- $\beta 3$ nanoreservoirs, 
specific histological staining were performed on cryostat sectioned samples. For Safranin-O/Fast Green staining, the samples were rinsed with distilled water and dipped in a solution of Fast Green $(0.02 \% \mathrm{~m} / \mathrm{v})$, acetic acid $(1 \% \mathrm{~m} / \mathrm{v})$, and Safranin-O $(0.1 \% \mathrm{~m} / \mathrm{v})$. For Alcian Blue staining, the samples were rinsed with distilled water and a solution of $2 \%(\mathrm{~m} / \mathrm{v})$ Alcian Blue (Sigma-Aldrich) at $\mathrm{pH} 4.2$ was added during $2 \mathrm{~h}$ at room temperature. Alizarin Red staining was performed by dipping samples in distilled water and then in a solution of $1 \%(\mathrm{~m} / \mathrm{v})$ Alizarin red (Sigma-Aldrich) ( $\mathrm{pH} \mathrm{1)}$ during 20 minutes at room temperature. Samples were then rinsed with distilled water. For further observations with bright field microscope (Leica DM 4000B), samples were mounted with Histolaque $\mathrm{LMR}^{\circledR}$ (LaboModerne, France).

\section{Quantitative reverse transcriptase PCR (QRT-PCR)}

To analyze quantitatively the effect of jellyfish implants equipped with TGF- $\beta 3$ nanoreservoirs on the chondrogenic differentiation of MSCs, quantitative RT-PCR was performed by measuring specific genes of the articular cartilage tissue (SOX9, RUNX2, COLL2 (Collagen II), ACAN (Aggrecan)). After 14 days of culture, the total RNA was extracted from MSCs cultured on implants containing (F) or not (NF) TGF- $\beta 3$ nanoreservoirs, with the high pure RNA Isolation Kit (Roche). The retrotranscription was then performed using the iScriptTM reverse Transcription Supermix (BioRad, Marnes-la-Coquette, France). The Real-time PCR reaction was then carried out using the iTaqTM Universal $\mathrm{SYBR}^{\circ} \mathrm{G}$ reen super mix (Biorad) and the CFX cycler system (BioRad) with the following cycle conditions: an initial denaturation step of $95^{\circ} \mathrm{C}$ for 2 minutes was performed, followed by 39 cycles of denaturation at $95^{\circ} \mathrm{C}$ for 5 seconds, annealing at $60^{\circ} \mathrm{C}$ during 30 seconds and extension at $65^{\circ} \mathrm{C}$ for 5 seconds. For each test, $\mathrm{n}=3$. Statistical significance was determined by a t-test. The primers used were:

\section{ACTIN $\quad$ B $\quad\left(5^{\prime}-\right.$ GATGAGATTGGCATGGCTTT-3'/5'-} CACCTTCACCGTTCCAGTTT-3'),

COLL2 (5'-CGTCCAGATGACCTTCCTACG-3' ${ }^{\prime}, / 5^{\prime}-$ TGAGCAGGGCCTTCTTGAGT-3'),

ACAN $\quad\left(5^{\prime}-\right.$ TCCCCTGCTATTTCATCGAC - 3/5' CCAGCAGCACTACCTCCTTC- ${ }^{\prime}$ ),

SOX9( $5^{\prime}$ - G G A A T G T T T C A G C A G C C A A T - 3/ 5 ' TGGTGTTCTGAGAGGCACAG-3'),

\section{RUNX2 (5'-CCAACCCACGAATGCACTATC-3'/5'-TAGT-} GAGTGGTGGCGGACATAC-3').

\section{Results}

\section{Design of a therapeutic active nanostructured Jellyfish collagen type II implant}

To develop an active implant for cartilage regeneration, we used a new source of collagen type II (Jellyfish, Jellagen ${ }^{\oplus}$ ) and attempted to make it active by adding TGF- $\beta 3$ nanoreservoirs. We have first prepared the jellyfish collagenic II material by lyophilization and observed, by Scanning Electron Microscopy (SEM), the formation of the porous material made of smooth collagen type II sheets (Figure 1A). We have then functionalized this jellyfish collagenic II implant by incorporation of TGF- $\beta 3$ into the nanoreservoirs using chitosan as excipient. Our results indicated clearly that we were able to build active nanocontainers on jellyfish collagenic II implant (Figure 1B).

\section{Biocompatibility of the designed active implant}

To analyze the biocompatibility of this nanostructured implant with human mesenchymal stem cells (hMSCs), we evaluated their metabolic activity during growth on either non-active (NF) or TGF- $\beta 3$ active (F) implants (Figure 1C). The metabolic activity of hMSCs was constant over the culture period for the $\mathrm{F}$ and the NF implants (From D7 to D21 $\mathrm{p}=0.131$ for $\mathrm{F}$, and $\mathrm{p}=0.645$ for NF). Furthermore, no significant differences in metabolic activity were observed between the $\mathrm{F}$ and the NF implants at each time of culture period (Figure 1C), showing that addition of TGF- $\beta 3$ nanoreservoirs doesn't interfere with the activity of hMSCs. These results showed that we were able to design a biocompatible nanoactive TGF- $\beta 3$ implant, using collagen type II from jellyfish in the presence of hMSCs.

\section{Chondrogenic differentiation ability of the designed active implant in the presence of hMSCs}

To evaluate the potentiality of the jellyfish collagen II type implant for chondrogenic differentiation of hMSCs, and to analyze the effect of TGF- $\beta 3$ nanoreservoirs on this differentiation, we performed quantitative RT-PCR, indirect immunofluorescence and histology (Figure 2). At 14 days of culture, the NF and the F implants expressed the chondrogenic specific genes SOX9, COLL2, ACAN, and RUNX2 (Figure 2). Interesting results were observed for the COLL2 gene, significantly $(\mathrm{p}=0.084$ ) increased on the $\mathrm{F}$ implant (Figure 2). This indicates clearly that the TGF- $\beta 3$ nanoreservoirs improved the capacity of hMSCs to secrete collagen II (Figure 2), thus accelerating their chondrogenic differentiation. Concerning the specific protein expression of the cartilage tissue, we performed indirect immunofluorescence after 21 days in vitro and observed the chondrogenic differentiation of the hMSCs (Figure 3). Our results undoubtedly show the expression of Sox 9 (Figure 3A and $3 \mathrm{E}$ ) and Runx2 (Figure $3 \mathrm{D}$ and $3 \mathrm{H}$ ) growth factors, and the matrix proteins secretion of aggrecan (Figure $3 \mathrm{~B}$ and $3 \mathrm{~F}$ ) and collagen II (Figure $3 \mathrm{C}$ and $3 \mathrm{G})$. These results obtained by indirect immunofluorescence confirmed the observations after genes expression studies, since collagen II protein was more expressed at day 21 in presence of TGF- $\beta 3$ nanoreservoirs (Figure $3 \mathrm{G}$ ) compared to native jellyfish material (Figure 3C). Furthermore, it appeared that Sox 9 transcription factor was also increased for hMSCs cultured on the active implant (Figure 3A and 3E). As noted in QRT-PCR, expression level of Aggrecan and Runx2 didn't varied for cells cultured on TGF- $\beta 3$ active implant (Figure $3 \mathrm{~F}$ and $3 \mathrm{H}$ ). This chondrogenic differentiation was also confirmed by using specific staining of the cartilage tissue (Figure 4). After 14 and 21 days in vitro, we observed an increase in the Glycosaminoglycans (GAGs) secretion when the implants were equipped with TGF- $\beta 3$ nanoreservoirs, visible by a high Safranin-O (Compare Figure $4 \mathrm{~A}$ and $4 \mathrm{~B}$ with Figure $4 \mathrm{G}$ and $4 \mathrm{H}$ ). This difference was observed at D14 (Compare Figure 4A with Figure 4G). The Alcian Blue staining also confirmed the GAGs secretion in the active (F) and non-active (NF) implants (Figure 4C, 4D, 4I and $4 \mathrm{~J})$. Alizarin staining was negative in the two conditions (Figure $4 \mathrm{E}$, $4 \mathrm{~F}, 4 \mathrm{~K}$ and $4 \mathrm{~L}$ ) and revealed that calcium was non deposited during culture time, showing that TGF- $\beta 3$ doesn't accelerate the osteogenic differentiation of hMSCs. These results showed clearly the potential of the TGF- $\beta 3$ nanoactive collagen type II implant for the chondrogenic differentiation and cartilage repair using hMSCs derived from the bone marrow.

\section{Discussion}

With the advent of third generation biomaterials, it is now well recognized that cells, materials, and growth factors form an indispensable prerequisite to improve current approaches of tissue repair. In this work, we developed a new strategy for the regenerative nanomedicine of articular cartilage, based on a jellyfish collagen- type II 
Citation: Pugliano M, Vanbellinghen X, Schwinté P, Benkirane-Jessel N, Keller L (2017) Combined Jellyfish Collagen Type II, Human Stem Cells and Tgf-B3 as a Therapeutic Implant for Cartilage Repair. J Stem Cell Res Ther 7: 382. doi: 10.4172/2157-7633.1000382
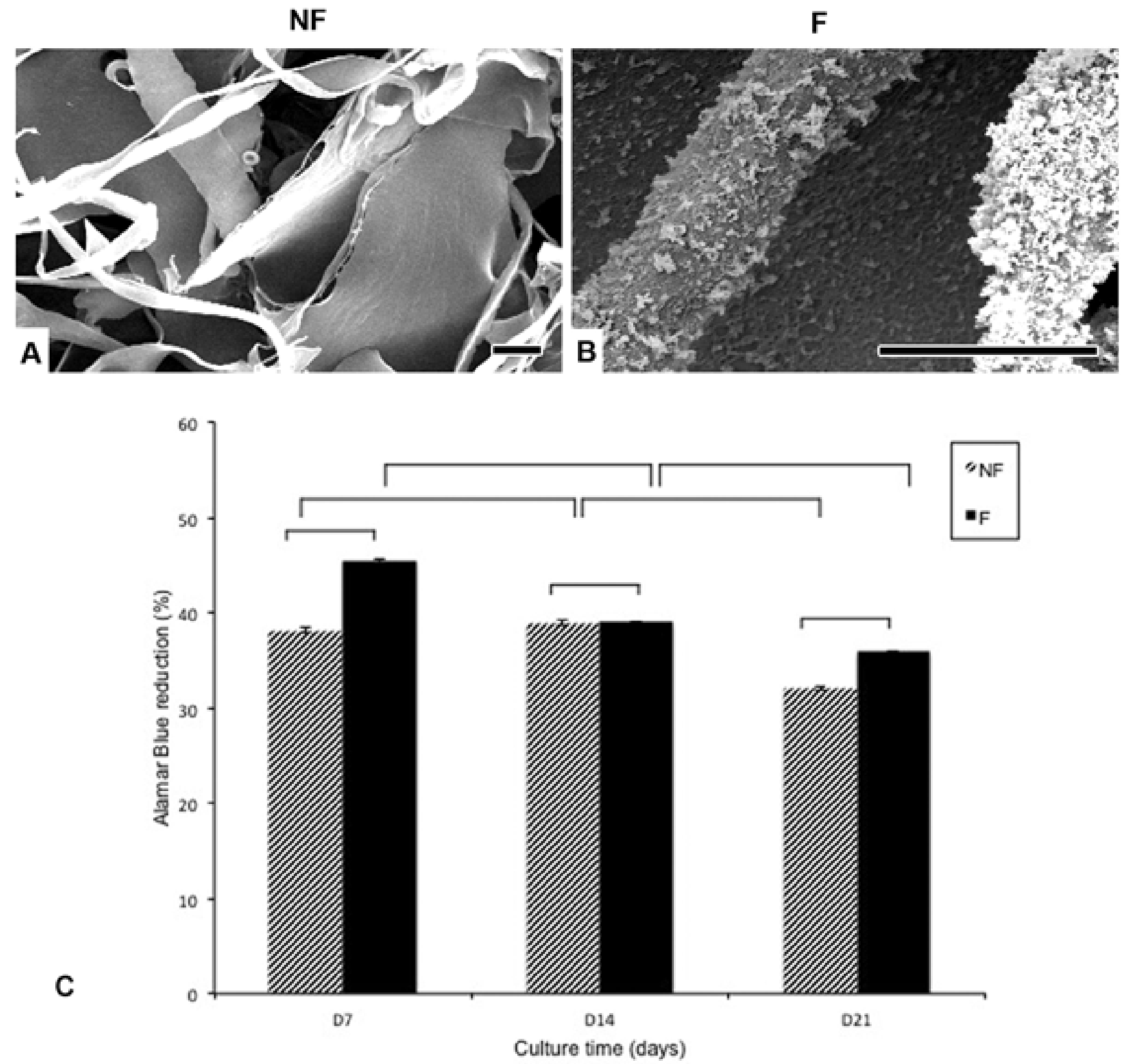

Figure 1: Design of a therapeutic active nanostructured collagen II implant for cartilage regeneration. Scanning electron microscopy images of the porous jellyfish collagen type II implant (Jellagen ${ }^{\circledR}$ ) (A). Visualization of the therapeutic TGF- $\beta 3$ nanoreservoirs on the collagen type II implant after nanoreservoirs technology processing (B). Metabolic activity of human mesenchymal stem cells (hMSCs) growing on the native (NF) and the TGF- $\beta 3$ active (F) Collagen type II implants. To evaluate their biocompatibility with hMSCs, the \% of Alamar Blue 8 reduction was determined at D7, D14, and D21 after seeding ( $n=3)(C)$. All values were expressed as mean \pm SEM. Differences were considered significant at $95 \% \mathrm{Cl}\left({ }^{* * *} p<0.01=\right.$ extremely significant; ${ }^{* *} p<0.05=v e r y$ significant; * $p>0.1=$ significant $)$. Scale bars $=5 \mu \mathrm{m}$. Abbreviations: D: Days; F: TGF- 33 Functionalized Implant; hMSCs: Human Mesenchymal Stem Cells; NF: Native Implant (not functionalized); SEM: Standard Error of the Mean; TGF- $\beta 3$ : Transforming Growth Factor- $\beta 3$.

material doped with TGF- $\beta 3$ and autologous MSCs. Proteins from the TGF- $\beta$ family play a central role in the endochondral development from early to terminal stages, and are essential actors in the cartilage tissue maintenance [24]. Particularly, the role of the TGF- $\beta 3$ is well recognized in the cartilage tissue engineering domain, as the loss of this growth factor in tissue induces chondrocyte hypertrophy, ultimately resulting in cartilage degeneration [33].
Moreover, this molecule is also implicated in the hypertrophy of MSCs, as it could preserve adipose derived stem cells chondrogenic differentiation from hypertrophy [34] and improve chondrogenesis by increasing the secretion of sulfated Glycosaminoglycans (GAGs) and collagen II $[35,36]$. Furthermore, TGF- $\beta$ superfamily is an epigenetic regulator of chondrogenesis by stimulating Sox9-regulated genes inactivated by chromatin in condensed state [37]. Epigenetic 

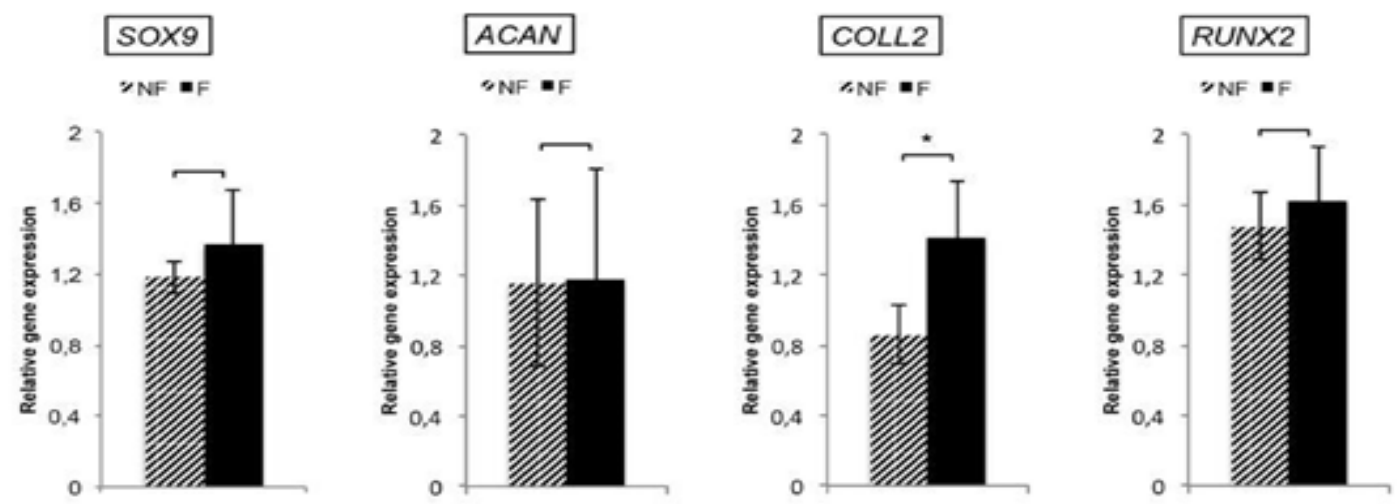

Figure 2: Chondrogenic genes expression of human mesenchymal stem cells on the TGF- $\beta 3$ active implant. Quantitative expression of genes specific of the articular cartilage tissue (SOX9, COLL2, ACAN, RUNX2) analyzed by QRT-PCR after 14 days of culture on the native (NF) and the TGF- 33 active (F) Collagen type II implants

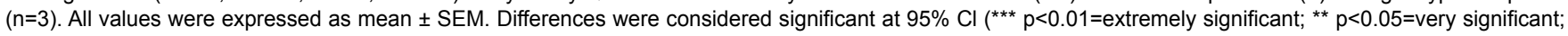
${ }^{*} p>0.1=$ significant).

Abbreviations: ACAN: Aggrecan; COLL2: Collagen of type II; F: TGF- 33 Functionalized Implant; NF: Native Implant; SEM: Standard Error of the Mean; RUNX2: Runt-related Transcription Factor 2; SOX9: Sex Determining Region Y-box 9; TGF- $\beta 3$ : Transforming Growth Factor $\beta 3$.

modifications are critical in chondrogenic differentiation, particularly H3K9 methyltransferases play an essential role in the hypertrophic and prehypertrophic state of MSCs, constituting an indispensable effector in their reprogramming and thus in their behaviour [38-42]. Changes at the epigenetic scale being considered as markers of pluripotency, it will be relevant to analyse epigenetic state of hMSCs cultured on the active TGF- $\beta 3$ implant to observe its influence on epigenetic variations and chondrogenic differentiation. As this growth factor can exert therapeutic effects on cartilage repair, groups attempted to develop active strategies by using TGF- $\beta 3$ for the promotion of chondrogenesis [35]. Regarding the difficulties associated to in vivo delivery of active molecules, a large amount of studies using TGF- $\beta 3$ improving chondrogenesis are based on plasmid or adenoviral transfection [43], direct integration of the molecule in materials $[20,22,23]$ or direct infusion of material [44]. Unfortunately, these kinds of approaches could lead to inaccurate regulation of the active molecule delivery, and side effects (osteophyte formation, fibrosis and swelling of the synovial) at the implantation site $[45,46]$. Thus, the huge impact that the TGF- $\beta 3$ could have in case of articular repair is becoming relevant [35] and we chose to adapt it to our strategy of nanoreservoirs allowing cell-contact dependent local delivery of active molecules [26-29]. The in vivo half-life of TGF- $\beta 3$ is very short $[47,48]$, and its efficient delivery after implantation remains challenging, as the in vivo environment leads to rapid removal of the protein from the wound site, loss of its bioactivity, or its low availability. To overcome these constraints, the nanoreservoirs strategy used in this work to increase the chondrogenesis of MSCs, was performed using heparin molecules as chaperones. TGF- $\beta 3$ contains a heparinbinding site able to potentiate its activity $[49,50]$. Indeed, the strategy of nanoreservoirs used here aims to protect TGF- $\beta 3$ from degradation, via heparin binding and chitosan entrapment within nanoreservoirs.

It is established that the use of chondrocytes associated with MSCs improves their differentiation via paracrine factors [31,51-54]. Among these factors, TGF- $\beta 3$ is secreted by chondrocytes [55]. The proposed use of growth factor nanocontainers can substitute the role of secreting chondrocytes, making TGF- $\beta 3$ available for promoting chondrogenesis of MSCs. Today, the developed therapeutics for articular cartilage repair focus on the use of autologous chondrocytes [3-6].
In the osteoarticular cell therapy domain, autologous MSCs are used (ChondrogenTM (Osiris therapeutics), but these cells are injected directly into the joint capsule, with the aim to modulate inflammation in case of osteoarthritis [56]. However for the repair and regeneration of articular cartilage with human MSCs, the use of a biomaterial, focusing cells at the defect site, is necessary. To closer mimic the natural cues of articular cartilage, we used the jellyfish collagen type II material (Jellagen ${ }^{\circ}$ ), offering a tridimensional environment, increasing cell-cell interactions and known to enhance chondrogenesis of MSCs [57]. This easy non-mammalian source of collagen type II ( $R$. pulmo) offers a larger cell attachment in three-dimensional conformation, and the lack of integrin-binding sites probably leads to an alternative binding mechanism allowing cells to keep their round shape and preventing them from dedifferentiation. By using collagen type II from jellyfish we could overcome the limitations associated to bovine or porcine MACI (matrix-induced chondrocyte implantation) implants, such as fibrous cartilage formation and risks of zoonosis (Bovine spongiform encephalopathy). Thus, marine collagen type II from jellyfish is a very suitable and promising material for the development of articular cartilage tissue repair implants.

The association of MSCs with an active material to form an implant of the third generation represents today an essential strategy with real impact fitting the clinical market of articular repair, promising the amelioration of surgical procedures and recovery of patients. To facilitate the clinical approach of this smart active implant, we used clinical applicable MSCs, well proliferating in vitro and differentiating in contact with biomaterials functionalized with nanoreservoirs of growth factors [26,29-31]. We showed here that this strategy of TGF- $\beta 3$ nanoreservoirs is biocompatible with hMSCs, and promotes the secretion of GAGs and collagen II, showing that the active jellyfish implant represents an efficient strategy to promote the cartilage regeneration.

\section{Conclusion}

We showed here that we were able to dope a jellyfish collagen type II implant, developed for cartilage regeneration, with therapeutic molecules. As the TGF- $\beta 3$ growth factor is a well-known effector of 
Citation: Pugliano M, Vanbellinghen X, Schwinté P, Benkirane-Jessel N, Keller L (2017) Combined Jellyfish Collagen Type II, Human Stem Cells and Tgf-B3 as a Therapeutic Implant for Cartilage Repair. J Stem Cell Res Ther 7: 382. doi: 10.4172/2157-7633.1000382

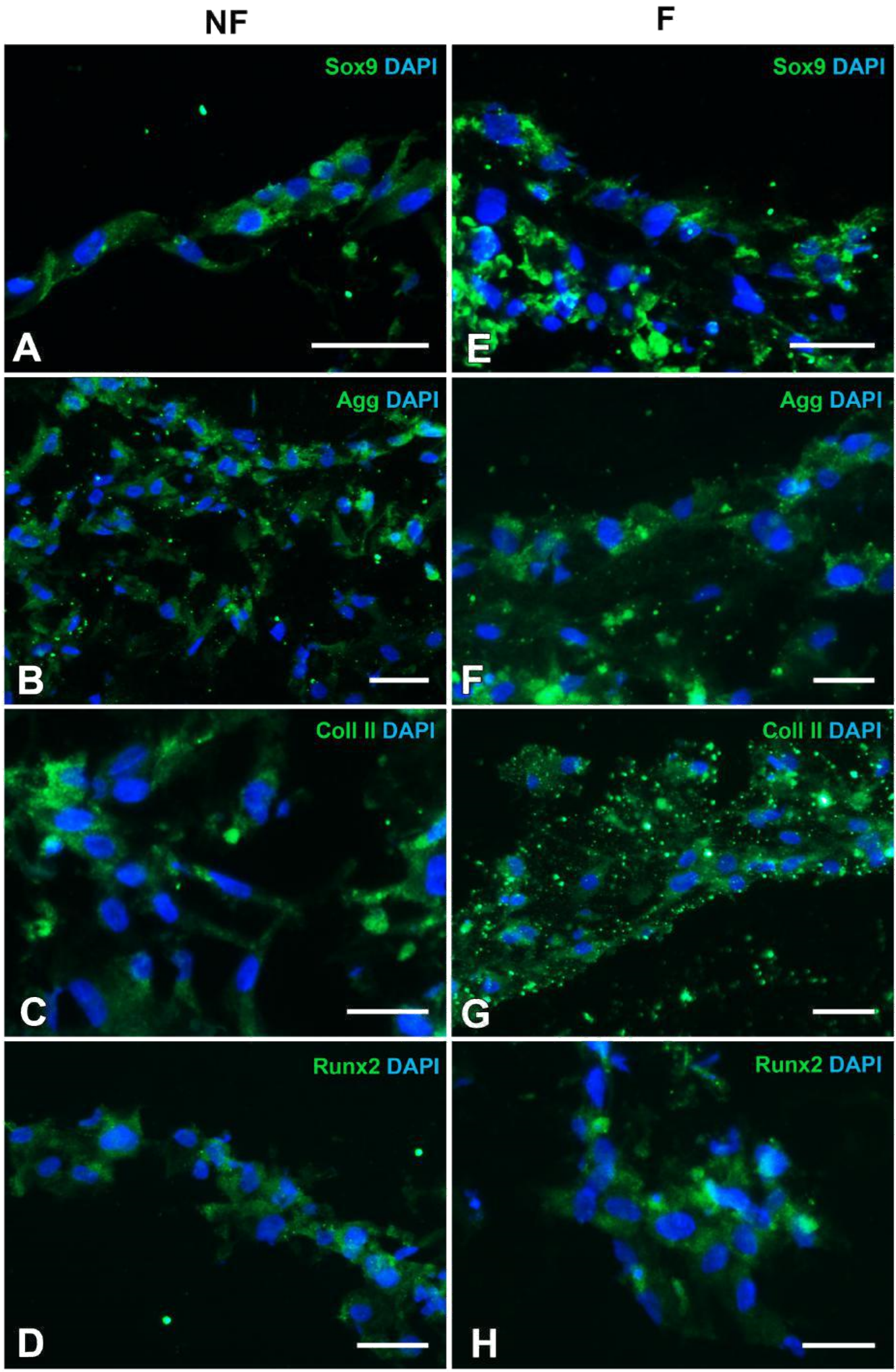

Figure 3: Chondrogenic proteins expression of human mesenchymal stem cells on the TGF- $\beta 3$ active implant. Expression of proteins specific of the articular cartilage tissue visible in green (A-H): Sox9 (A, E), Aggrecan (B, F), Collagen II (C, G) and Runx2 (D, H), observed by indirect immunofluorescence after 21 days of culture on the native (NF) (A-D) and the active (F) collagenic implants (E-H). Nuclei are visible in blue by DAPI staining. Scale bars=50 $\mu \mathrm{m}$.

Abbreviations: Agg: Aggrecan; Coll II: Collagen of type II; DAPI: 4',6'-diamidino-2-phenylindole; F: TGF- $\beta 3$ functionalized implant; NF: Native Implant; Runx2: Runtrelated transcription factor 2; Sox9: Sex Determining region Y-box 9; TGF- $\beta 3$ : Transforming Growth Factor $\beta 3$. 


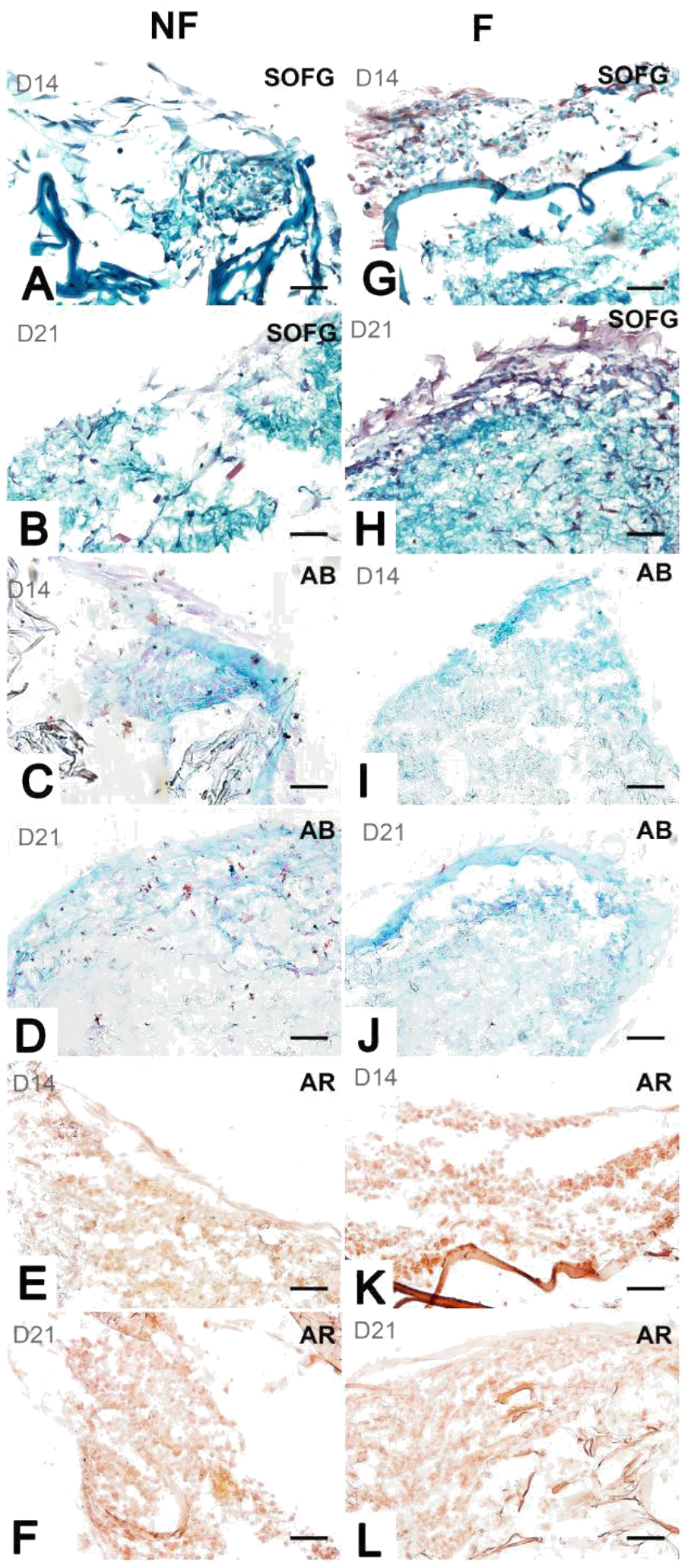

Figure 4: GAGs secretion of human mesenchymal stem cells on the TGF- $\beta 3$ active implant. Histological staining showing glycosaminoglycans secretion in red by Safranin-O/Fast Green (A, B, G, H) and in blue by Alcian Blue (C, D, I, J) after 14 and 21 days of culture on the native (NF) and the TGF- $\beta 3$ active (F) implants. Mineralization was also evaluated by an Alizarin Red staining after 14 and 21 days of culture on both materials $(E, F, K, L)$. Scale bars $=50 \mu \mathrm{m}$.

Abbreviations: AB: Alcian Blue; AR: Alizarin Red; D: Days; F: TGF- $\beta 3$ functionalized implant; NF: Native Implant; SOFG: Safranin-O/Fast Green; TGF- $\beta 3$ : Transforming Growth Factor $\beta 3$. 
Citation: Pugliano M, Vanbellinghen X, Schwinté P, Benkirane-Jessel N, Keller L (2017) Combined Jellyfish Collagen Type II, Human Stem Cells and Tgf-B3 as a Therapeutic Implant for Cartilage Repair. J Stem Cell Res Ther 7: 382. doi: 10.4172/2157-7633.1000382

the chondrogenesis signalling way, this molecule represented an ideal candidate to produce therapeutic implants for improving cartilage regeneration. By using the nanoreservoirs strategy for entrapping this active molecule, we developed successful active therapeutic implants for regenerative medicine. This approach, developed here, could be adjusted with other therapeutic applicable cells, tissues or drugs. Our innovative therapeutic medical implant, as an adaptable medical device, is an adjustable technology, which can be tune by using different kinds of cells, active drugs and biomaterials and thereby apply for the regeneration of other tissues.

\section{Competing Interests}

The authors report no conflicts of interest in this work.

\section{Authors' Contributions}

MP: Conception, design collection and assembly of the data, analysis and interpretation, XV: formation of jellyfish implants, PS: Conception of nanoreservoirs, NJ and LK: Conception and design, assembly of the data, analysis and interpretation, writing of the manuscript.

\section{Acknowledgement}

This work was funded by INSERM and the authors are indebted to Faculté de Chirurgie Dentaire de Strasbourg for financial support. The authors thank Valérie Demais (INCl, Strasbourg) for her great help with SEM, Jellagen $®$ PTY LTD (Cardiff , United Kingdom) for jellyfish collagen type II and Nicolas Humbert (CNRS, UMR7213, Strasbourg, France) for his help with lyophilization.

\section{References}

1. Jacobi M, Villa V, Magnussen RA, Neyret $P$ (2011) MACl - a new era? Sports Med Arthrosc Rehabil Ther Technol 3: 10. [PubMed]

2. Abdel-Sayed P, Pioletti DP (2015) Strategies for improving the repair of focal cartilage defects. Nanomedicine 10: 2893-2905. [PubMed]

3. Volz M, Schaumburger J, Frick H, Grifka J, Anders S (2017) A randomized controlled trial demonstrating sustained benefit of Autologous Matrix-Induced Chondrogenesis over microfracture at five years. Int Orthop pp: 1-8

4. Niethammer TR, Holzgruber M, Gülecyüz MF, Weber P, Pietschmann MF, et al. (2017) Matrix based autologous chondrocyte implantation in children and adolescents: a match paired analysis in a follow-up over three years postoperation. Int Orthop 41: 343-350. [PubMed]

5. Petri M, Broese M, Liodakis E, Guenther D, Krettek C, et al. (2013) CaReS $₫$ (MACT) versus microfracture in treating symptomatic patellofemoral cartilage defects: a retrospective matched-pair analysis. J Orthop Sci 18: 38-44. [PubMed]

6. Nixon AJ, Rickey E, Butler TJ, Scimeca MS, Moran N, et al. (2015) A chondrocyte infiltrated collagen type $\mathrm{I} / \mathrm{III}$ membrane (MACI ${ }^{\circledR}$ implant) improves cartilage healing in the equine patellofemoral joint model. Osteoarthritis Cartilage 23 648-660. [PubMed]

7. Pustlauk W, Paul B, Brueggemeier S, Gelinsky M, Bernhardt A (2015) Modulation of chondrogenic differentiation of human mesenchymal stem cells in jellyfish collagen scaffolds by cell density and culture medium: Chondrogenic differentiation of hMSCs in jellyfish collagen scaffolds. J Tissue Eng Regen Med [PubMed]

8. Sewing J, Klinger M, Notbohm H (2015) Jellyfish collagen matrices conserve the chondrogenic phenotype in two- and three-dimensional collagen matrices: Jellyfish collagen matrices conserve the chondrogenic phenotype. J Tissue Eng Regen Med 11: 916-925. [PubMed]

9. Hoyer B, Bernhardt A, Lode A, Heinemann S, Sewing J, et al. (2014) Jellyfish collagen scaffolds for cartilage tissue engineering. Acta Biomater 10: 883-892. [PubMed]

10. Caldwell KL, Wang $J(2015)$ Cell-based articular cartilage repair: the link between development and regeneration. Osteoarthritis Cartilage 23: 351-362. [PubMed]
11. von der Mark K, Gauss V, von der Mark H, Müller P (1977) Relationship between cell shape and type of collagen synthesised as chondrocytes lose their cartilage phenotype in culture. Nature 267: 531-532. [PubMed]

12. Benya PD, Padilla SR, Nimni ME (1978) Independent regulation of collagen types by chondrocytes during the loss of differentiated function in culture. Cell 15: 1313-1321. [PubMed]

13. Magne D, Vinatier C, Julien M, Weiss P, Guicheux J (2005) Mesenchymal stem cell therapy to rebuild cartilage. Trends Mol Med 11: 519-526. [PubMed]

14. Woods A, Wang G, Beier F (2007) Regulation of chondrocyte differentiation by the actin cytoskeleton and adhesive interactions. J Cell Physiol 213: 1-8. [PubMed]

15. Beane OS, Darling EM (2012) Isolation, characterization, and differentiation of stem cells for cartilage regeneration. Ann Biomed Eng 40: 2079-2097. [PubMed]

16. Seo S, Na K (2011) Mesenchymal stem cell-based tissue engineering for chondrogenesis. J. Biomed. Biotechnol 2011: 806891. [PubMed]

17. Nejadnik H, Hui JH, Feng Choong EP, Tai BC, et al. (2010) Autologous bone marrow-derived mesenchymal stem cells versus autologous chondrocyte implantation: an observational cohort study. Am J Sports Med 38: 1110-1116. [PubMed]

18. Daw R, Tonzani S (2009) Biomaterials. Nature 462:425. [PubMed]

19. Yang SS, Jin LH, Park SH, Kim MS, Kim YJ, et al. (2016) Extracellular Matrix (ECM) Multilayer Membrane as a Sustained Releasing Growth Factor Delivery System for rhTGF-B3 in Articular Cartilage Repair. Burns JS, editor. PLOS ONE 11: e0156292. [PubMed]

20. Fisher MB, Belkin NS, Milby AH, Henning EA, Söegaard N, et al. (2016) Effects of Mesenchymal Stem Cell and Growth Factor Delivery on Cartilage Repair in a Mini-Pig Model. Cartilage 7: 174-84. [PubMed]

21. Pan Q, Li W, Yuan X, Rakhmanov $Y$, Wang $P$, et al. (2016) Chondrogenic effect of cell-based scaffold of self-assembling peptides/PLGA-PLL loading the hTGFß3 plasmid DNA. J Mater Sci Mater Med 27: 19. [PubMed]

22. Matsiko A, Levingstone TJ, Gleeson JP, O'Brien FJ (2015) Incorporation of TGFbeta 3 within collagen-hyaluronic acid scaffolds improves their chondrogenic potential. Adv Healthc Mater 4: 1175-1159. [PubMed]

23. Krüger JP, Machens I, Lahner M, Endres M, Kaps C (2014) Initial boost release of transforming growth factor- $\beta 3$ and chondrogenesis by freeze-dried bioactive polymer scaffolds. Ann Biomed Eng 42: 2562-2576. [PubMed]

24. Wang W, Rigueur D, Lyons KM (2014) TGF $\beta$ signaling in cartilage development and maintenance: TGF $\beta$ signaling in cartilage. Birth Defects Res C Embryo Today 102: 37-51. [PubMed]

25. Kim SH, Kim SH, Jung Y (2015) TGF- $\beta 3$ encapsulated PLCL scaffold by supercritical CO2-HFIP co-solvent system for cartilage tissue engineering. J Control Release 213: e100-101. [PubMed]

26. Palomares CM, Ferrand A, Facca S, Fioretti F, Ladam G, et al. (2012) Smart hybrid materials equipped by nanoreservoirs of therapeutics. ACS Nano 6: 483490. [PubMed]

27. Eap S, Ferrand A, Schiavi J, Keller L, Kokten T, et al. (2013) Collagen implants equipped with "fish scale"-like nanoreservoirs of growth factors for bone regeneration. Nanomedicine (Lond). 9: 1253-1261 [PubMed]

28. Eap S, Keller L, Ferrand A, Schiavi J, Lahiri D, et al. (2013) Nanomechanical properties of active nanofibrous implants after in vivo bone regeneration. Nano LIFE 4: 9.

29. Eap S, Keller L, Schiavi J, Huck O, Jacomine L, et al. (2015) A living thick nanofibrous implant bifunctionalized with active growth factor and stem cells for bone regeneration. Int J Nanomed 10: 1061-1075. [PubMed]

30. Keller L, Wagner Q, Schwinté P, Jessel NB (2015) Double compartmented and hybrid implant outfitted with well-organized $3 \mathrm{D}$ stem cells for osteochondral regenerative nanomedicine. Nanomedicine (Lond) 10: 2833-2845. [PubMed]

31. Keller L, Wagner Q, Pugliano M, Breda P, Ehlinger M, et al. (2015) Bi-layered Nano Active Implant with Hybrid Stem Cell Microtissues for Tuned Cartilage Hypertrophy. J Stem Cell Res Ther 1: 00004.

32. Keller L, Schwinté P, Gomez-Barrena E, Arruebo M, Benkirane-Jessel N (2017) Smart Implants as a Novel Strategy to Regenerate Well-Founded Cartilage. Trends Biotechnol 35: 8-11. [PubMed] 
Citation: Pugliano M, Vanbellinghen X, Schwinté P, Benkirane-Jessel N, Keller L (2017) Combined Jellyfish Collagen Type II, Human Stem Cells and Tgf-B3 as a Therapeutic Implant for Cartilage Repair. J Stem Cell Res Ther 7: 382. doi: 10.4172/2157-7633.1000382

33. Wu M, Chen G, Li YP (2016) TGF- $\beta$ and BMP signaling in osteoblast, skeletal development, and bone formation, homeostasis and disease. Bone Res 4 : 16009. [PubMed]

34. Hennig T, Lorenz H, Thiel A, Goetzke K, Dickhut A, et al. (2007) Reduced chondrogenic potential of adipose tissue derived stromal cells correlates with an altered TGFbeta receptor and BMP profile and is overcome by BMP-6. J Cell Physiol 211: 682-691. [PubMed]

35. Tang QO, Shakib K, Heliotis M, Tsiridis E, Mantalaris A, et al. (2009) TGFbeta3: A potential biological therapy for enhancing chondrogenesis. Expert Opin Biol Ther 9: 689- 701. [PubMed]

36. Gonzalez-Fernandez T, Tierney EG, Cunniffe GM, O'Brien FJ, Kelly DJ (2016) Gene Delivery of TGF- 33 and BMP2 in an MSC-Laden Alginate Hydrogel for Articular Cartilage and Endochondral Bone Tissue Engineering. Tissue Eng Part A 22: 776-787. [PubMed]

37. Furumatsu T, Asahara $H$ (2010) Histone acetylation influences the activity of Sox9-related transcriptional complex. Acta Med Okayama 64: 351-357. [PubMed]

38. Ideno H, Shimada A, Imaizumi K, Kimura H, Abe M, et al. (2013) Predominant expression of H3K9 methyltransferases in prehypertrophic and hypertrophic chondrocytes during mouse growth plate cartilage development. Gene Expr Patterns 13: 84-90. [PubMed]

39. Zhang T, Termanis A, Özkan B, Bao XX, Culley J, et al. (2016) G9a/GLP Complex Maintains Imprinted DNA Methylation in Embryonic Stem Cells. Cell Rep 15: 77-85. [PubMed]

40. Yang J, Kaur K, Ong LL, Eisenberg CA, Eisenberg LM (2015) Inhibition of G9a Histone Methyltransferase Converts Bone Marrow Mesenchymal Stem Cells to Cardiac Competent Progenitors. Stem Cells Int 2015: 270428. [PubMed]

41. Collas P, Noer A, Sørensen AL (2008) Epigenetic Basis for the Differentiation Potential of Mesenchymal and Embryonic Stem Cells. Transfus Med Hemother 35: 205-215. [PubMed]

42. Dahl JA, Duggal S, Coulston N, Millar D, Melki J, et al. (2008) Genetic and epigenetic instability of human bone marrow mesenchymal stem cells expanded in autologous serum or fetal bovine serum. Int J Dev Biol 52: 10331042. [PubMed]

43. Zheng D, Dan Y, Yang S, Liu G, Shao Z, et al. (2015) Controlled chondrogenesis from adipose-derived stem cells by recombinant transforming growth factor- $\beta 3$ fusion protein in peptide scaffolds. Acta Biomaterial 1: 191-203. [PubMed]

44. Lee CH, Cook JL, Mendelson A, Moioli EK, Yao H, et al. (2010) Regeneration of the articular surface of the rabbit synovial joint by cell homing: a proof of concept study. Lancet 376: 440-448. [PubMed]
45. Saraf A, Mikos AG (2006) Gene delivery strategies for cartilage tissue engineering. Adv Drug Deliv Rev 58: 592-603. [PubMed]

46. Lam J, Lu S, Kasper FK, Mikos AG (2015) Strategies for Controlled Delivery of Biologics for Cartilage Repair. Adv Drug Deliv Rev 84: 123-134. [PubMed]

47. Kaminska B, Wesolowska A, Danilkiewicz M (2005) TGF beta signalling and its role in tumour pathogenesis. Acta Biochim Pol 52: 329-337. [PubMed]

48. Moioli EK, Hong L, Guardado J, Clark PA, Mao JJ (2006) Sustained Release of TGF 33 from PLGA Microspheres and Its Effect on Early Osteogenic Differentiation of Human Mesenchymal Stem Cells. Tissue Eng 12: 537-546. [PubMed]

49. Park JS, Woo DG, Yang HN, Lim HJ, Chung HM, et al. (2008) Heparin-Bound Transforming Growth Factor- $\beta 3$ Enhances Neocartilage Formation by Rabbit Mesenchymal Stem Cells. Transplantation 85: 589-596. [PubMed]

50. Park JS, Woo DG, Yang HN, Na K, Park KH (2009) Transforming growth factor $\beta-3$ bound with sulfate polysaccharide in synthetic extracellular matrix enhanced the biological activities for neocartilage formation in vivo. J Biomed Mater Res A 91: 408-415. [PubMed]

51. Lai JH, Kajiyama G, Smith RL, Maloney W, Yang F (2013) Stem cells catalyze cartilage formation by neonatal articular chondrocytes in 3D biomimetic hydrogels. Sci Rep 3: 3553. [PubMed]

52. Cooke ME, Allon AA, Cheng T, Kuo AC, Kim HT, et al. (2011) Structured threedimensional co-culture of mesenchymal stem cells with chondrocytes promotes chondrogenic differentiation without hypertrophy. Osteoarthr. Cartil 19: 12101218. [PubMed]

53. Hubka KM, Dahlin RL, Meretoja VV, Kasper FK, Mikos AG (2014) Enhancing chondrogenic phenotype for cartilage tissue engineering: monoculture and coculture of articular chondrocytes and mesenchymal stem cells. Tissue Eng Part B Rev 20: 641-654. [PubMed]

54. Meretoja VV, Dahlin RL, Kasper FK, Mikos AG (2012) Enhanced chondrogenesis in co-cultures with articular chondrocytes and mesenchymal stem cells. Biomaterials 33: 6362-6369. [PubMed]

55. Villiger PM, Lotz M (1992) Differential expression of TGF beta isoforms by human articular chondrocytes in response to growth factors. J Cell Physiol 151 318-325. [PubMed]

56. Evans CH, Kraus VB, Setton LA (2013) Progress in intra-articular therapy. Nat Rev Rheumatol 10: 11-22. [PubMed]

57. Li WJ, Tuli R, Okafor C, Derfoul A, Danielson KG, et al. (2005) A threedimensional nanofibrous scaffold for cartilage tissue engineering using human mesenchymal stem cells. Biomaterials 26: 599-609. [PubMed] 